\title{
Kenneth Arnette Responds
}

To the Editor:

In his letter to the Journal, V. Krishnan disagrees with my interpretation of near-death experience (NDEs) in the context of the mind/body problem (Arnette, 1992). Krishnan writes that I consider Michael Sabom's (1982) evidence of accurate visual perception during NDEs to be proof of dualism. Further, Krishnan writes that I have ignored the problems of mind-brain interaction and infinite regression of mind function. I would like to address these three points.

Sabom (1982) presented several examples of NDEs in which the NDEr had visual perceptions of events in the operating room (OR), perceptions that were verified via examination of the medical records. In my earlier article (Arnette, 1992), I pointed out that this was a crucial step in NDE research, since these accurate visual perceptions cannot be explained by materialistic theories. I do not consider these data to be proof, per se, of mind/body dualism; rather, I consider them to constitute an anomaly (Kuhn, 1970) which cannot be explained within the materialistic paradigm.

Krishnan $(1982,1993)$ has accepted the visual accuracy in reports of NDEs, and has proposed that out-of-body vision "may involve receptors and/or brain mechanisms different from those involved in normal vision" (1982, p. 21), and that out-of-body vision "may represent an attempt to compensate for the reduction of sensory input which may occur during the dying process" (p. 22). Thus, while not denying the accuracy of these visual perceptions, Krishnan maintains that they can be explained physiologically and therefore do not constitute an anomaly in the materialistic paradigm. Krishnan does not, however, suggest a way in which eyeless sight could occur.

In considering Krishnan's argument, one should be aware that in most of Sabom's OR NDE cases, the patient's eyes were taped shut or head and body draped with sheets; in several cases the patient's heart had stopped and the medical team was working frantically to revive the patient. Thus, it is highly doubtful that the patient could observe the surrounding events with the eyes or any other receptors, due to physical obstructions, if nothing else.

But more importantly, the stoppage of the heart and the ensuing oxygen deficit in the brain present serious problems for any materialist explanation of accurate NDE sensation, perception, and memory. The human brain is a massive consumer of oxygen. For an adult, 
the brain receives 15 to 20 percent of the total cardiac output of blood volume (Powers, 1990). The brain is entirely dependent on the oxygen and glucose delivered by the circulatory system, oxidizing the glucose to provide for all its energy needs; very little glucose is stored as a reserve (Powers, 1990). Therefore, the cessation of blood flow and the resulting anoxia (complete lack of oxygen in the brain) severely inhibit the central nervous system (CNS) chemical reactions necessary for memory and consciousness. In fact, "the chief clinical feature of abrupt and global CNS anoxia is immediate loss of consciousness (within seconds), and irreversible damage may begin after only 2-4 minutes" (Morris and Ferrendelli, 1990, p.365-366).

Among the first areas of the brain to be affected by anoxia is the hippocampus, which is critical to the formation and storage of longterm memory (Morris and Ferrendelli, 1990). Even hypoxia (decreased availability of oxygen in the brain) alone is sufficient to cause damage to hippocampal neurons, and memory deficit is a major consequence of this condition (Morris and Ferrendelli, 1990). In view of the preceding facts, one would expect patients to have no consciousness during, and no memories of, their resuscitations. The detailed and accurate information in the long-term memory of Sabom's subjects is a direct contradiction of the observations and predictions of modern neuropsychology and is impossible from an organic perspective.

The NDE data therefore do indeed constitute an anomaly for materialists. Krishnan's suggestion that investigation of body-based eyeless sight could yield new knowledge about memory mechanisms is an understatement; all of physical and biological science would be turned upside down by the discovery that neurochemical reactions could proceed without their reactants: oxygen and glucose.

Krishnan's second point is that I have ignored the problem of mindbrain interaction, which is supposed to be an unsolvable problem due to the dualist's conception of the mind as nonphysical. Krishnan goes on to say that since dualists cannot answer this objection, the question of interaction is pointless. It is true that I did not propose an interaction model in my first article. The model did not yet exist at that time, but its seeds had begun to take root. I have now completed the first stage in building an interactionist model (Arnette, in press).

Very briefly, the theory of essence proposes that what we call "mind" is in fact the intermingling and interaction of the essence with the brain. The essence is indeed nonphysical, in that it is not composed of matter. This definition does not, however, preclude interaction with physical entities, because the essence, like the body, 
is associated with a time-varying electromagnetic field. It is the interaction of the brain and essence electric fields that allows "mind" and "body" to interact. The paper describing this model (Arnette, in press) elaborates on this basic idea by demonstrating correlations and analogies between NDE data and well-known electromagnetic phenomena from physics and chemistry.

Krishnan's third point is essentially that by removing the workings of the mind from a physiological basis, I am raising the problem of infinite regression with regard to mind functioning. I would like to make it as clear as possible that I do believe that the conscious human mind has a physiological basis, but that the physical basis alone is not sufficient to explain the NDE data. There is more to the picture than neurons and chemical reactions. It is true, however, that I regard the essence as the seat of thought and consciousness, and in that sense I have not tried to answer the question "What is consciousness?" But this is only one step removed from the physical world, not an infinite number of steps. I believe that if we look anew at the NDE, accepting it not as hallucination or wishful thinking but rather as a window into a different reality, we might make progress in understanding consciousness in its essential form.

\section{References}

Arnette, J. K. (1992). On the mind/body problem: The theory of essence. Journal of Near-Death Studies, 11, 5-18.

Arnette, J. K. (In press). The theory of essence. Part II: An electromagnetic-quantum mechanical model of interactionism. Journal of Near-Death Studies.

Krishnan, V. (1982). Out-of-the-body vision. Parapsychology Review, 13(2), 21-22.

Krishnan, V. (1993). The physical basis of out-of-body vision. Journal of Near-Death Studies, 11, 257-260.

Kuhn, T. (1970). The structure of scientific revolutions. Chicago, IL: University of Chicago Press.

Morris, J., and Ferrendelli, J. (1990). Metabolic encephalopathy. In Pearlman, A., and Collins, R. (Eds.), Neurobiology of disease. New York, NY: Oxford University Press.

Powers, W. (1990). Stroke. In Pearlman, A., and Collins, R. (Eds.), Neurobiology of disease. New York, NY: Oxford University Press.

Sabom, M. (1982). Recollections of death: A medical investigation. New York, NY: Harper and Row.

J. Kenneth Arnette, Ph.D. Department of Psychology

Colorado State University

Ft. Collins, Colorado 80523 